\title{
Acute Methemoglobinemia after Endoscopy
}

\author{
Max Bayard, MD, Jeff Farrow, MD, FCCP, and Fred Tudiver, MD
}

Acute methemoglobinemia may be caused by topical anesthetics and other oxidizing medications commonly prescribed by Family Physicians. Without knowledge of this potentially lethal condition, delay in diagnosis and treatment is likely. Methemoglobinemia should be considered in any patient presenting with cyanosis, particularly after the use of oxidizing medications.

We describe a case of methemoglobinemia in a patient who presented with cyanosis after endoscopy. This case followed otherwise uncomplicated upper gastrointestinal (GI) endoscopy. The diagnosis was delayed several hours because the physicians treating the patient did not consider the possibility of acute methemoglobinemia.

\section{Case Report}

The patient was a 26-year-old white woman who was sent to the emergency department for evaluation of cyanosis immediately after esophagogastroduodenoscopy. Before the onset of cyanosis, the procedure had been uncomplicated. Benzocaine spray had been applied, and the patient was routinely sedated with meperidine and midazolam. While in recovery, the nurses noted that the patient became cyanotic and mildly short of breath.

The patient was transferred to the emergency department, where she was markedly cyanotic. She was initially given naloxone and flumazenil without improvement in her cyanosis. Her blood pressure was $72 / 48 \mathrm{~mm} \mathrm{Hg}$, and she was tachypneic. Cardiac and pulmonary exams were otherwise unremarkable. Hemoglobin and hematocrit were $12.6 \mathrm{~g} / \mathrm{dL}$ and 0.384 , respectively. The results of a basic chemistry panel were normal. Arterial blood gas on room air showed $\mathrm{pH}$ of $7.349, \mathrm{pCO}_{2}$ was $40.8 \mathrm{~mm}$ $\mathrm{Hg}, \mathrm{pO}_{2}$ was $97.5 \mathrm{~mm} \mathrm{Hg}$, and $\mathrm{HCO}_{3}$ was 21.8 $\mathrm{mEq} / \mathrm{L}$. Oxygen saturation $\left(\mathrm{SaO}_{2}\right)$ by pulse oximetry was $83 \%$. The patient was placed on $100 \%$

Submitted, revised, 2 September 2003.

From the Departments of Family Medicine (MB, FT) and Internal Medicine (JF), Quillen College of Medicine, East Tennessee State University, Johnson City. Address correspondence to Max Bayard, MD, ETSU Family Medicine Associates, 917 W. Walnut St., Johnson City, TN 37604. oxygen, but there was no improvement in the $\mathrm{SaO}_{2}$. A chest radiograph was unremarkable and results of a ventilation-perfusion scan were normal. At that time, a pulmonologist was consulted. He recommended checking a methemoglobin level, which was subsequently found to be elevated at $23.6 \%$.

Because the patient was tachypneic and hypotensive, she was admitted to the intensive care unit and given $90 \mathrm{mg}$ of intravenous methylene blue $(2 \mathrm{mg} / \mathrm{kg}$ ) over 5 minutes. Repeat methemoglobin level 3 hours later was near zero. The patient was discharged the following day in stable condition without any further complications.

\section{Discussion}

Primary care physicians (Family Physicians and General Internists) perform many of the endoscopies in this country (eg, approximately $17 \%$ of upper GI endoscopies in Medicare beneficiaries). ${ }^{1}$ These procedures often involve the use of oxidizing agents such as benzocaine spray, which have a demonstrated, although rare risk of causing acute methemoglobinemia. Topical benzocaine spray has been shown to improve patient tolerance of upper GI endoscopy. ${ }^{2}$ It is generally used in conjunction with conscious sedation. The potential complication of methemoglobinemia has prompted at least one author to question whether the use of benzocaine spray should be continued. ${ }^{3}$

\section{Pathology}

Methemoglobin is produced naturally by the body when the iron component of the heme molecule is oxidized from the ferrous $\left(\mathrm{Fe}^{2+}\right)$ state to the ferric $\left(\mathrm{Fe}^{3+}\right)$ state. Only the ferrous state has significant oxygen-carrying capacity. Normal levels of methemoglobin are less than $1 \%$. Reduction to the ferrous state occurs through the NADH-cytochrome $b_{5}$ reductase system. Oxidizing agents, such as benzocaine, cause other substances to lose an electron, hence the change from the ferrous state to the ferric state.

When susceptible persons are exposed to certain oxidizing agents, excessive production of methemoglobin may occur. This may result from a ge- 
netic deficiency of cytochrome $b_{5}$ reductase, although there have also been reports of acute methemoglobinemia in patients with normal levels of cytochrome $b_{5}$ reductase. $^{4}$ Other oxidizing medications that may elicit this response include topical anesthetics, dapsone, metoclopramide, nitrates, rifampin, and sulfonamides.

Acute methemoglobinemia has been reported in several clinical situations. Although the condition is rare, there are case reports of its occurrence after upper GI endoscopy, transesophageal echocardiography, orogastric tube placement, and intubation when topical benzocaine is applied. ${ }^{4-6}$ There are reports of cases resulting from the use of intravenous nitroglycerine. ${ }^{7}$ Eutectic mixture of local anesthetics (EMLA) cream has also been implicated. ${ }^{8}$ A recent review of cases of clinically significant methemoglobinemia after use of topical benzocaine spray in patients undergoing transesophageal echocardiogram reported an estimated incidence of $0.1 \%$.

\section{Clinical Findings}

Signs and symptoms of methemoglobinemia correlate with the levels of methemoglobin in the blood. Cyanosis becomes apparent at about 10\% concentration. Fatigue, confusion, tachypnea, and worsening tachycardia occur in the range of $30 \%$ to $50 \%$. Coma, seizures, arrhythmias, and acidosis may occur at levels greater than $50 \%$. Levels above $70 \%$ may be fatal. Symptoms may be worse if the patient is anemic, or if the person has underlying cardiac or pulmonary disease. ${ }^{10}$

\section{Diagnosis}

The diagnosis of methemoglobinemia should be considered in a patient presenting with cyanosis without a known cardiac or pulmonary cause. The likelihood is increased in patients with exposure to oxidizing drugs. Failure to promptly diagnose methemoglobinemia can be fatal.

Certain laboratory findings suggest the presence of abnormal hemoglobin, which occurs in methemoglobinemia. Oxygen saturation measured by pulse oximetry is usually in the range of $80 \%$ to $85 \%$ regardless of the severity of methemoglobinemia. Routine arterial blood gas analysis is used to determine partial pressure of oxygen $\left(\mathrm{pO}_{2}\right)$, which can be used to calculate oxygen saturation in the blood. However, measurement of $\mathrm{pO}_{2}$ is not affected by the presence of methemoglobin. There- fore, a pulse oximeter reading that is inconsistent with oxygen saturation calculated using the $\mathrm{pO}_{2}$ measurement is suggestive of methemoglobinemia. This occurred in the patient described in this case. Her $\mathrm{pO}_{2}$ was $97.5 \mathrm{~mm} \mathrm{Hg}$, which would normally result in an oxygen saturation of greater than $90 \%$; however, the patient's saturation by pulse oximetry was only $83 \%$.

The diagnosis of methemoglobinemia is confirmed by measuring the methemoglobin level of arterial blood through co-oximetry. Routine pulse oximetry only distinguishes deoxyhemoglobin from oxyhemoglobin, but co-oximetry differentiates oxyhemoglobin, deoxyhemoglobin, carboxyhemoglobin, and methemoglobin. If methemoglobinemia is suspected, arterial blood should be drawn for blood gas analysis and use of co-oximetry should be specifically requested. Co-oximetry requires a separate analyzer and is available at larger hospitals but may not be available at some smaller hospitals. If a blood gas specimen must be sent to a referral laboratory for co-oximetry, the specimen should be kept on ice and transported as quickly as possible.

A quick, bedside method of differentiating methemoglobinemia from deoxyhemoglobinemia is the so-called "filter paper test." Arterial blood is drawn and a few drops placed on filter paper. Deoxyhemoglobin is initially a deep purple, but on exposure to oxygen, becomes bright red. Methemoglobin gives blood a chocolate brown color that does not change when exposed to oxygen.

\section{Treatment}

The appropriate treatment of acute toxic methemoglobinemia is determined by the level of methemoglobin and the presence or absence of symptoms. Methemoglobin levels of less than 20\% generally do not require specific treatment except for removal of the causative agent. Symptomatic patients with levels of $20 \%$ to $30 \%$ or higher should receive IV methylene blue at a dose of 1 to $2 \mathrm{mg} / \mathrm{kg}$ over 5 minutes. At therapeutic doses, methylene blue is metabolized to form a reducing agent that facilitates the reduction of methemoglobin. A single dose is usually sufficient, but the dose may be repeated in 1 hour if necessary. Methylene blue is readily available and is stocked in most hospital pharmacies for this sort of emergency. Patients with a deficiency of G6PD should not receive methylene blue because this can result in 
hemolysis. Exchange transfusion should be considered in people with G6PD deficiency. ${ }^{11}$

\section{Summary}

Acute methemoglobinemia is a rare but potentially life-threatening complication of the use of certain oxidizing medications. There are numerous case reports of this condition after upper GI endoscopy and other procedures in which topical anesthetics are used. Physicians who perform these procedures, and those who are likely to see patients emergently, should be aware of this complication. A finding highly suggestive of methemoglobinemia is a discrepancy between the $\mathrm{SaO}_{2}$ and the saturation calculated from $\mathrm{pO}_{2}$. Rapid diagnosis and treatment, if necessary, may be life-saving.

We thank Kaethe Ferguson for assistance with manuscript preparation.

\section{References}

1. Ackermann RJ. Performance of gastrointestinal tract endoscopy by primary care physicians. Lessons from the US Medicare database. Arch Fam Med 1997;6: 52-8.

2. Froehlich F, Schwizer W, Thorens J, Kohler M, Gonvers JJ, Fried M. Conscious sedation for gastroscopy: patient tolerance and cardiorespiratory parameters. Gastroenterology 1995;108:697-704.
3. Gunaratnam NT, Vazquez-Sequeiros E, Gostout CJ, Alexander GL. Methemoglobinemia related to topical benzocaine use: is it time to reconsider the empiric use of topical anesthesia before sedated EGD? Gastrointest Endosc 2000;52:692-3.

4. Dinneen SF, Mohr DN, Fairbanks VF. Methemoglobinemia from topically applied anesthetic spray. Mayo Clin Proc 1995;69:886-8.

5. Grauer SE, Giraud GD. Toxic methemoglobinemia after topical anesthesia for transesophageal echocardiography. J Am Soc Echocardiogr 1996;9:874-6.

6. Udeh C, Bittikofer J, Sum-Ping ST. Severe methemoglobinemia on reexposure to benzocaine. J Clin Anesth 2001;13:128-30.

7. Bojar RM, Rastegar H, Payne DD, et al. Methemoglobinemia from intravenous nitroglycerin: a word of caution. Ann Thorac Surg 1987;43:332-4.

8. Touma S, Jackson JB. Lidocaine and prilocaine toxicity in a patient receiving treatment for mollusca contagiosa. J Am Acad Dermatol 2001;44:399-400.

9. Novaro GM, Aronow HD, Militello MA, Garcia MJ, Sabik EM. Benzocaine-induced methemoglobinemia: experience from a high-volume transesophageal echocardiography laboratory. J Am Soc Echocardiogr 2003;16:170-75.

10. Wright RO, Lewander WJ, Woolf AD. Methemoglobinemia: etiology, pharmacology, and clinical management. Ann Emerg Med 1999;34:646-56.

11. Ellenhorn MJ. Methylene blue. Ellenhorn's medical toxicology, 2nd ed. Baltimore: Williams \& Wilkins; 1997. 